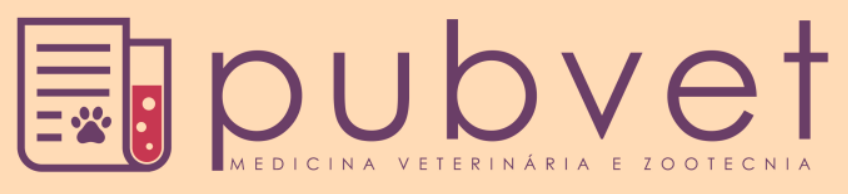

https://doi.org/10.22256/pubvet.v12n4a70.1-9

\title{
Produtividade de cultivares forrageiros no nordeste brasileiro
}

\author{
Mariah Tenorio de Carvalho Souza ${ }^{\bullet *}$, Janaina Azevedo Martuscello 22 \\ ${ }^{1}$ Bolsista de Desenvolvimento Científico, Tecnológico e Regional, FAPEAL/CAPES/CNPq - Maceió, Alagoas - Brasil - E- \\ mail: mariah_tenorio@hotmail.com *Autor para correspondência \\ ${ }^{2}$ Professor da Universidade Federal de São João del-Rei, Departamento de Zootecnia. São João del-Rei, MG - Brasil. E-mail: \\ janainamartuscello@yahoo.com.br
}

RESUMO. Com o objetivo de se avaliar e selecionar forrageiras adaptadas ao ecossistema agreste, foram avaliados 4 cultivares da espécie Panicum maximum (Mombaça, Milenio, Tanzânia e Massai) e 3 cultivares de Urochloa brizantha (Xaraés, Marandu e Piatã). Os experimentos foram conduzidos na Universidade Federal de Alagoas/Campus Arapiraca em um delineamento inteiramente casualizado com três repetições em parcelas de $4,0 \mathrm{~m}^{2}$. As cultivares de $U$. brizantha foram semeadas à lanço no campo experimental e quando as plantas atingiram cerca de $30 \mathrm{~cm}$ foram colhidas a $15 \mathrm{~cm}$. As cultivares da espécie $P$. maximum foram postas para germinar em bandeja contendo substrato agrícola comercial e posteriormente foram transplantadas para a área experimental e foram colhidas de acordo com a altura de cada cultivar da seguinte forma: as cultivares Milênio e Mombaça foram cortadas com altura de $90 \mathrm{~cm}$ e resíduo de $15 \mathrm{~cm}$; a cultivar Tanzania foi cortada com 70 $\mathrm{cm}$ de altura e resíduo de $30 \mathrm{~cm}$ e a cultivar Massai foi cortada com $50 \mathrm{~cm}$ de altura e resíduo de $20 \mathrm{~cm}$. Após o corte as plantas foram separadas em lâmina, colmo + bainha e material morto e após secagem foram avaliadas quanto a produção de massa seca total, massa seca foliar, de colmos e material morto. Para as avaliações de produção um quadrado de $0,25 \mathrm{~m}^{2}$ foi alocado aleatoriamente nas parcelas quando as plantas atingiram a altura de corte. Imediatamente após os cortes as plantas foram pesadas e separadas em lâmina, colmo + bainha e material morto, em seguida os componentes botânicos foram secos em estufa de ventilação forçada a $55^{\circ} \mathrm{C}$ até peso constante. A partir dos resultados estimou-se a produtividaade. As avaliações bromatológicas foram realizadas no Near-infrared Reflectance Spectrocospy (NIRS) no Laboratório de Nutrição Animal da Embrapa Gado de Corte. Os resultados indicam que as cultivares Marandu e Xaraés (U. brizantha) e Tanzânia (P. maximum) são aquelas de maior produtividade no ecossistema Agreste.

Palavras chave: Biomassa, braquiária, bromatologia, panicum, qualidade

\section{Productivity of forage cultivars in Northeast of Brazil}

ABSTRACT. With the objective of evaluating and selecting adapted forage for wild ecosystem, we evaluated 04 cultivars of the species Panicum maximum (Mombaça, Milenio, Tanzania and Massai) and 03 cultivars of Urochloa brizantha (Xaraés, Marandu and Piatã). The experiments were conducted at the Federal University of Alagoas / Campus Arapiraca in a completely randomized design with three replications in plots of $4.0 \mathrm{~m}^{2}$. The cultivars of $U$. brizantha was sown in the field to haul experimental and when the plants reached about $30 \mathrm{~cm}$ to $15 \mathrm{~cm}$ were collected. Cultivars of the species P.maximum were germinated in trays containing commercial substratum and were later transplanted into the experimental area and were taken according to the height of each cultivar as follows: Milenio cultivars and Mombasa were cut to a height of $90 \mathrm{~cm}$ and 15 residual $\mathrm{cm}$, to cultivate Tanzania was cut to $70 \mathrm{~cm}$ high and $30 \mathrm{~cm}$ residue and cultivate Massai was cut $50 \mathrm{~cm}$ in height and $20 \mathrm{~cm}$ residue. After cutting the plants were separated into blade, stem 
and dead material after drying and were evaluated to produce total dry mass, dry mass of leaf, stem and dead material. Production assessments for a square of $0,25 \mathrm{~m}^{2}$ was allocated randomly to the plots when the plants reached the height of cut. Immediately after the cuts the plants were weighed and separated into blade, stem and dead material, then the botanical components were dried in a forced air oven at $55^{\circ} \mathrm{C}$ until constant weight. From the results, we estimated the productivity. To bromatological assessments, were held in Near-Infrared Reflectance Spectrocospy (NIRS) in Animal Nutrition Laboratory at Embrapa Beef Cattle. The results indicate that cultivars Marandu and Xaraés (U. brizantha) and Tanzania (P. maximum) are those of greater productivity in the ecosystem Agreste.

Keywords: Biomass, brachiaria, bromatology, panicum, quality

\section{Productividad de cultivos forrajeros en el nordeste brasileño}

RESUMEN. Con el objetivo de evaluar y seleccionar forrajeras adaptadas al ecosistema agreste, se evaluaron 4 cultivares de la especie Panicum maximum (Mombasa, Milenio, Tanzania y Massai) y 3 cultivares de Urochloa brizantha (Xaraés, Marandu y Piatã). Los experimentos fueron conducidos en la Universidad Federal de Alagoas / Campus Arapiraca en un delineamiento completamente aleatorio con tres repeticiones en parcelas de $4,0 \mathrm{~m}^{2}$. Los cultivos de $U$. brizantha fueron sembrados a lance en el campo experimental y cuando las plantas alcanzaron cerca de $30 \mathrm{~cm}$ fueron recolectadas a $15 \mathrm{~cm}$. Los cultivos de la especie $P$. maximum fueron colocadas para germinar en bandeja conteniendo sustrato agrícola comercial, posteriormente fueron trasplantadas en el área experimental y fueron recolectadas de acuerdo con la altura de cada cultivo de la siguiente forma: los cultivos Milenio y Mombasa fueron cortados con altura de $90 \mathrm{~cm}$ y residuo de $15 \mathrm{~cm}$; el cultivo de Tanzania fue cortado con $70 \mathrm{~cm}$ de altura y residuo de $30 \mathrm{~cm}$; el cultivo Massai fue cortado con $50 \mathrm{~cm}$ de altura y residuo de $20 \mathrm{~cm}$. Después del corte las plantas fueron separadas en lámina, colmo + vaina y material muerto y después del secado fueron evaluadas en cuanto a la producción de masa seca total, masa seca foliar, de colmos y material muerto. Para las evaluaciones de producción un cuadrado de $0,25 \mathrm{~m}^{2}$ fue asignado aleatoriamente en las parcelas cuando las plantas alcanzaron la altura de corte. Inmediatamente después de los cortes las plantas fueron pesadas y separadas en lámina, colmo + vaina y material muerto, luego los componentes botánicos fueron secos en estufa de ventilación forzada a $55^{\circ} \mathrm{C}$ hasta peso constante. A partir de los resultados se estimó la productividad. Las evaluaciones bromatológicas se realizaron en el Near-infrarro Reflectance Spectrocospy (NIRS) en el Laboratorio de Nutrición Animal de la Embrapa Ganado de Corte. Los resultados indican que las cultivares Marandu y Xaraés ( $U$. brizantha) y Tanzania ( $P$. maximum) son aquellas de mayor productividad en el ecosistema Agreste.

Palabras clave: Biomasa, braquial, bromatología, panicum, calidad

\section{Introdução}

A atividade agropecuária brasileira tem tido uma importante participação na economia, sendo uma componente relevante do Produto Interno Bruto - PIB e da geração de riqueza para o país. A pecuária bovina, por sua vez, tem ganhado grande valor, tanto no cenário interno quanto externo, uma vez que o Brasil possui o maior rebanho comercial bovino do mundo, movimentando cerca de 2,25 bilhões de dólares por ano (FAO, 2015). Em relação à produção de leite, a produção anual média por estabelecimento pecuário, por exemplo, passou de 9,86 mil litros para 15,98 mil litros, um aumento de $62 \%$. A produção nacional de leite passou de 17,93 bilhões de litros em 1996 para 21,43 bilhões de litros em 2006, de acordo com o IBGE, mantendo a tendência de aumento registrado nos anos anteriores, estando o maior aumento da produção de leite na região Sul do Brasil (51,6\%) (ANUALPEC, 2017).

De forma geral, os estados do Nordeste apresentam baixa produtividade animal e os sistemas de produção não adotam tecnologias de alto nível, talvez devido ao baixo volume de informações geradas para atender as necessidades específicas das diferentes localidades da região (Ferrazza et al., 2015). 
Sabendo que a pastagem constitui a principal fonte de alimentos dos bovinos pode-se dizer que a produção de carne e leite no país é baseada quase que exclusivamente em pastagens de gramíneas e leguminosas forrageiras (Ferraz \& Felício, 2010). O Brasil dispõe de cerca de 170 milhões de hectares de pastagens, cerca de $20 \%$ do território nacional. Desse total mais de $60 \%$ das áreas pastoris são constituídas por pastagens cultivadas e cerca de 100 milhões de hectares fazem parte da região Centro-Oeste do Brasil que possui a maior área de estabelecimentos agropecuários do País (Ferraz \& Felício, 2010). Aproximadamente 85\% dessas pastagens são ocupadas por forrageiras da espécie Urochloa e P. maximum, sendo estas forrageiras de maior interesse entre os pecuaristas por sua alta produtividade. No entanto, $80 \%$ das áreas cultivadas estão em processo de degradação e o desenvolvimento de novas cultivares forrageiras com plantas mais competitivas, menos exigentes em fertilidade do solo, com menor sazonalidade de produção e maior resistência à pragas e doenças, entre outros, assume importante papel para a pecuária nacional, visando o aumento da produtividade dos rebanhos, recuperação e diversificação das pastagens (Martuscello et al., $\underline{2007)}$.

O Brasil é hoje o maior produtor, exportador e consumidor de sementes forrageiras, em um mercado que movimenta cerca de 2,5 milhões de dólares ao ano (ANUALPEC, 2017) e o melhoramento de plantas forrageiras no Brasil hoje é uma realidade (Silva \& Nascimento Júnior, 2007). Ganhos expressivos de produtividade vêm sendo alcançados com o lançamento de novas cultivares. Ademais, a maioria das forrageiras lançadas no mercado tem como ecossistema principal, tanto para avaliação quanto para utilização o Brasil Central, ficando o Nordeste com poucas opções para diversificação. Nesse sentido, o lançamento de forrageiras mais competitivas e adaptadas a essa região certamente contribuirá para aumentos expressivos de produtividade. O primeiro passo para a melhoria da produtividade animal no Nordeste brasileiro seria a busca por forrageiras mais produtivas nas condições específicas de cada ecossistema dessa região.

As forrageiras nativas da região nordeste, embora extremamente adaptadas às condições edafoclimáticas da região, apresentam baixa produtividade, não raramente sendo observadas taxa de lotação nas pastagens da ordem de 0,2 UA/ha. Resultados obtidos por vários pesquisadores mostraram que o uso racional de plantas forrageiras adaptadas e selecionadas é viável e que essas forrageiras combinadas com a pastagem nativa permitem aumentos significativos na eficiência da produção animal no Nordeste brasileiro(Freitas et al., 2012).

Algumas espécies forrageiras têm tido destaque na pecuária nacional, dentre essas cita-se cultivares das gramíneas Urochloa sp. (Argenta et al., 2017) e P. maximum (Martuscello et al., 2015), sendo que esta última se destaca, principalmente pela elevada produtividade. Assim, a avaliação da produção e seleção de cultivares dessas espécies no agreste certamente contribuiria para o aumento na produtividade animal, uma vez que a forrageira adotada nos sistemas de produção seria aquela de maior adaptação ao meio.

Diante do exposto objetivou-se com este trabalho indicar forrageiras de elevada produção e qualidade para serem cultivadas nas condições edafoclimáticas do Agreste e determinar cultivares de $P$. maximum e $U$. brizantha mais adaptadas para a região do Agreste alagoano, avaliando as características produtivas e de qualidade.

\section{Material e Métodos}

O experimento foi realizado na Universidade Federal de Alagoas, Campus Arapiraca. O município de Arapiraca situa-se na região do agreste subsumido, onde o clima é do tipo As', segundo a classificação climática de Köppen \& Geiger (1928), com estação seca no verão e chuvas de outono/inverno. As amostras de solo foram coletadas em 27 de abril de 2009 e enviadas para análise. Os resultados da análise química do solo estão apresentados na Tabela 1.

Tabela 1. Características químicas de amostras de solo da camada de 0 a $20 \mathrm{~cm}$ de profundidade na área experimental.

\begin{tabular}{lr}
\hline Características químicas & Resultados \\
\hline $\mathrm{pH}\left(\mathrm{H}_{2} \mathrm{O}\right)$ relação 1:2,5 & 5,4 \\
$\mathrm{Ca}-\mathrm{KCl}-1 \mathrm{~mol} / \mathrm{L}\left(\mathrm{cmol}_{\mathrm{c}} / \mathrm{dm}^{3}\right)$ & 4,7 \\
$\mathrm{Mg}-\mathrm{KCl}-1 \mathrm{~mol} / \mathrm{L}\left(\mathrm{cmol}_{\mathrm{c}} / \mathrm{dm}^{3}\right)$ & 2,2 \\
$\mathrm{Al}-\mathrm{KCl}-1 \mathrm{~mol} / \mathrm{L}\left(\mathrm{cmol}_{\mathrm{c}} / \mathrm{dm}^{3}\right)$ & 0,0 \\
$\mathrm{H}+\mathrm{Al}$ - Acetato de cálcio $0,5 \mathrm{~mol} / \mathrm{L}\left(\mathrm{cmolc}_{\mathrm{d}} / \mathrm{dm}^{3}\right)$ & 4,0 \\
Soma das bases $\left(\mathrm{cmol}_{\mathrm{c}} / \mathrm{dm}^{3}\right)$ & 7,2 \\
Capacidade de troca de cátions $\left(\mathrm{cmol}_{\mathrm{c}} / \mathrm{dm}^{3}\right)$ & 11,2 \\
Saturação por bases $(\%)$ & 64,4 \\
P- $(\mathrm{ppm})$ & 68,0 \\
K- $(\mathrm{ppm})$ & 142,0 \\
\hline
\end{tabular}

Método EMBRAPA (2006) de análises de solo. 
Quatro cultivares da espécie $P$. maximum (Mombaça, Massai, Milênio e Tanzânia) e três cultivares de $U$. brizantha (Xaraés, Piatã e Marandu) foram utilizados no experimento. Os acessos de $P$. maximum foram postos a germinar em bandejas contendo substrato agrícola comercial em 22 de maio de 2009, enquanto que as cultivares de $U$. brizantha foram semeadas na própria área experimental. As mudas de $P$. maximum foram transplantadas para a área experimental em 08 de junho de 2009 , em parcelas de $4 \mathrm{~m} 2$. O delineamento utilizado foi o inteiramente casualizado com parcelas subdivididas no tempo, sendo as cultivares consideradas como parcelas e as estações do ano (água e seca) como subparcelas, com três repetições. $\mathrm{Na}$ transplantação procedeu-se adubação fosfatada nos sulcos de plantio em dose equivalente a $50 \mathrm{~kg} / \mathrm{ha}$ de P2O5. Em 30 de junho de 2006 foram realizadas as adubações potássicas e nitrogenada com doses equivalentes a $80 \mathrm{~kg} / \mathrm{ha}$ de $\mathrm{K}_{2} \mathrm{O}$ (cloreto de potássio) e $100 \mathrm{~kg} / \mathrm{ha}$ de $\mathrm{N}$ (ureia). Em 20 de julho foi realizado o corte de uniformização a $5 \mathrm{~cm}$ do solo.

Durante o período experimental, a altura do dossel foi monitorada mensalmente. A altura foi avaliada em três pontos aleatórios por unidade experimental, utilizando-se régua graduada em centímetros. A altura em cada ponto correspondeu à altura da curvatura das folhas em torno da régua, e a média desses pontos representou a altura média de cada cultivar. À medida que as plantas foram atingindo o estádio reprodutivo, também se teve o cuidado de medir a altura das plantas com inflorescência, ou seja, além da altura da curvatura das folhas, mediu-se a altura das plantas do nível do solo até o ponto mais alto da inflorescência.

Os cortes foram realizados de acordo com o desenvolvimento de cada cultivar. Assim, as plantas de capim Mombaça e capim Milênio foram cortadas a $40 \mathrm{~cm}$ do solo quando a altura do dossel atingiu $90 \mathrm{~cm}$. Plantas de capim Tanzânia eram cortadas aos $70 \mathrm{~cm}$ a uma altura de $30 \mathrm{~cm}$ do solo. As plantas de capim Massai foram cortadas quando a altura do dossel atingiu $50 \mathrm{~cm}$, com resíduo de $20 \mathrm{~cm}$. As cultivares de $U$. brizantha (marandu, piatã e xaraés) foram cortadas com 40 $\mathrm{cm}$ e deixado resíduo de $15 \mathrm{~cm}$. No total foram realizados cinco cortes para todas as cultivares, dos quais dois foram realizados no período seco e três no período das águas.

Para as avaliações de produção um quadrado de $1,0 \mathrm{~m}^{2}$ foi alocado aleatoriamente nas parcelas quando as plantas atingiram a altura de corte. Imediatamente após os cortes as plantas foram pesadas e separadas em lâmina, colmo + bainha e material morto, em seguida os componentes botânicos foram secos em estufa de ventilação forçada a $55^{\circ} \mathrm{C}$ até peso constante. A partir dos resultados estimou-se a produção de matéria seca total, matéria seca de folha, matéria seca de colmo e de material morto. Amostras foram moídas, identificadas e enviadas (1 g/planta) para as avaliações bromatológicas que foram feitas no Near-infrared Reflectance Spectrocospy (NIRS) do Laboratório de Nutrição Animal da Embrapa Gado de Corte, onde se procederam as análises de proteína bruta $(\mathrm{PB})$ de folhas, $\mathrm{PB}$ de colmo, fibra em detergente neutro (FDN) das folhas, FDN do colmo, fibra em detergente ácido (FDA) do colmo, digestibilidade in vivo da matéria orgânica (DIVMO) das folhas, DIVMO dos colmos, lignina da folha e lignina do colmo. Procedeu-se à análise de variância em delineamento em blocos casualizados, em esquema de parcela subdividida, com o objetivo de estimar os resíduos associados às parcelas e sub parcelas. As interações significativas entre os fatores foram desdobradas. Os dados experimentais foram submetidos a análise de variância e tiveram suas médias comparadas pelo teste de Tukey, adotando-se 0,05 como nível crítico de probabilidade para o erro tipo I.

\section{Resultados}

Observa-se na tabela 2 as características de cultivares de $P$. maximum nas diferentes épocas do ano. Apenas para a característica de MSMM foi observada diferença $(\mathrm{P} \leq 0,05)$ nas duas épocas do ano para as cultivares avaliadas.

Apesar da não significância na época das chuvas para a característica de MST, podem ser destacados os capins Mombaça e Massai pela alta produtividade com 1.347 e $1.301 \mathrm{~g} /$ parcela, respectivamente (Tabela 2); enquanto o capim Milênio apresentou menor proporção de MST.

Em relação a produção e $\mathrm{MM}$, a cultivar Milênio apresentou menor produtividade $(83,89$ $\mathrm{g} /$ parcela - Tabela 2).

Não foi observado efeito $(P>0,05)$ entre as cultivares Mombaça e Tanzânia para a variável MSMM produzindo cerca de 209,71 e 244,92 g/parcela, respectivamente no período crítico do ano. A cultivar Milênio se apresentou intermediária quando comparada às demais. 
Tabela 2. Características de produção de cultivares de P. maximum em diferentes épocas do ano no Agreste alagoano.

\begin{tabular}{lcccc}
\hline Característica & \multicolumn{3}{c}{ Cultivares } \\
\cline { 2 - 5 } & Milenio & Mombaça & Massai & Tanzania \\
\hline Época das secas & & & \\
Massa seca total (g/parcela) & $1.177,67$ & $1.347,11$ & $1.300,83$ & $1.295,97$ \\
Massa seca de lâminas (g/parcela) & 770,91 & $1.060,33$ & $1.175,08$ & $1.062,01$ \\
Massa seca de colmos (g/parcela) & 360,20 & 207,74 & 119,23 & 161,99 \\
Massa seca de material morto (g/parcela) & $33,89^{\mathrm{b}}$ & $66,86^{\mathrm{ab}}$ & $99,25^{\mathrm{a}}$ & $57,6^{\mathrm{ab}}$ \\
Época das secas & & & \\
Massa seca total (g/parcela) & & & $2.297,06$ \\
Massa seca de lâminas (g/parcela) & $1.890,08$ & $2.181,21$ & $1.581,67$ & $1.197,21$ \\
Massa seca de colmos (g/parcela) & $1.030,20$ & $1.213,91$ & 912,42 & 844,93 \\
Massa seca de material morto (g/parcela) & 707,76 & 756,59 & 592,65 & $244,92^{\mathrm{a}}$ \\
\hline
\end{tabular}

Médias seguidas da mesma letra na linha não diferem entre si pelo teste Tukey a 5\% de probabilidade para o erro tipo I.

As variáveis qualitativas das cultivares da espécie $P$. maximum no período das águas estão apresentadas na tabela 3 .

Não foi observada diferença $(\mathrm{P}>0,05)$ para as variáveis proteína bruta das folhas e fibra em detergente neutro do colmo entre as cultivares avaliadas. O capim Tanzânia apresentou maiores teores de proteína bruta das folhas $(16 \%)$ e de colmo $(7,6 \%)$ quando comparado às demais cultivares. Além disso, apresentou alta razão lâmina/colmo de 6,1. Ainda, a cultivar Massai apresentou menor valor para proteína do colmo e menor FDN das folhas (73\%).

Para a variável FDN das folhas das cvs. Milênio, Mombaça e Tanzânia apresentaram comportamento semelhante $(\mathrm{P}<0,05)$.

A digestibilidade in vitro da matéria orgânica das folhas dos capins Milêno e Tanzânia foram maiores $(\mathrm{P}<0,05)$ em detrimento das demais cultivares.

Tabela 3. Características de qualidade de cultivares de Panicum maximum no período de água no Agreste alagoano.

\begin{tabular}{|c|c|c|c|c|c|}
\hline \multirow{2}{*}{ Característica } & \multicolumn{4}{|c|}{ Cultivar } & \multirow{2}{*}{$\mathrm{CV}(\%)$} \\
\hline & Massai & Milênio & Mombaça & Tanzânia & \\
\hline Proteína Bruta Folhas & 14,96 & 15,43 & 14,40 & 15,56 & 5,52 \\
\hline Proteína Bruta colmo & $3,30^{\mathrm{c}}$ & $6,79^{b}$ & $6,73^{b}$ & $7,60^{\mathrm{a}}$ & 17,61 \\
\hline FDN $^{1}$ Folhas & $72,73^{b}$ & $75,23^{a}$ & $75,43^{a}$ & $73,56^{\text {a }}$ & 1,35 \\
\hline FDN $^{1}$ colmo & 84,00 & 81,13 & 82,63 & 80,33 & 2,11 \\
\hline FDA $^{2}$ folhas & 36,73 ab & $38,10^{\mathrm{a}}$ & 39,27 a & $34,93^{b}$ & 2,95 \\
\hline $\mathrm{FDA}^{2}$ colmo & $49,13^{b}$ & $53,86^{\mathrm{a}}$ & $52,33^{\text {a }}$ & $48,13^{\mathrm{b}}$ & 3,45 \\
\hline $\mathrm{DIVMO}^{3}$ folhas & $63,23^{\mathrm{b}}$ & $66,63^{a}$ & $63,73^{b}$ & $68,63^{\text {a }}$ & 1,60 \\
\hline DIVMO $^{3}$ colmos & $48,80^{\mathrm{b}}$ & $49,56^{\mathrm{b}}$ & $52,90^{\mathrm{a}}$ & $57,13^{a}$ & 4,73 \\
\hline Lignina folha & $2,9^{\mathrm{a}}$ & $3,3^{\mathrm{a}}$ & $3,4^{\mathrm{a}}$ & $3,03^{\mathrm{b}}$ & 5,33 \\
\hline Lignina colmo & $4,90^{\mathrm{b}}$ & $6,06^{\mathrm{a}}$ & $5,16^{\mathrm{b}}$ & $4,60^{\mathrm{b}}$ & 5,51 \\
\hline
\end{tabular}

Médias seguidas da mesma letra na linha não diferem entre si pelo teste Tukey a 5\% de probabilidade. ${ }^{1}$ Fibra em detergente neutro. ${ }^{2}$ Fibra em detergente ácido. ${ }^{3}$ Digestibilidade in vitro da matéria orgânica

Os capins Mombaça e Tanzânia tiveram maiores teores de digestibilidade in vitro da matéria orgânica de colmo correspondente aos valores $53 \%$ e $57 \%$, respectivamente (Tabela 3 ).

A interação das características de produtividade (matéria seca) nas cultivares não sofreram significância $(P>0,05)$ (Tabela 4). Entretanto, pode-se observar que a matéria seca dos colmos (MSC) na época seca apresentou-se elevada em todas as cultivares avaliadas.

Pode-se observar ainda, que não houve diferença $(\mathrm{P}>0,05)$ na produção de matéria seca total (MST) na época das secas. Na época das secas a cultivar Xaraés apresentou menores produtividades de matéria seca de colmo e matéria seca de material morto e apresentou maior matéria seca de lâmina. 
Tabela 4. Características de produção de cultivares de Urochloa brizantha em diferentes épocas do ano no Agreste alagoano.

\begin{tabular}{lccrr}
\hline \multirow{2}{*}{ Característica } & \multicolumn{3}{c}{ Cultivares } & \multirow{2}{*}{ CV (\%) } \\
\cline { 2 - 4 } Épocas das águas & Marandu & Xaraés & Piatã & \\
Massa seca total (g/parcela) & & & 8,81 \\
Massa seca de lâminas (g/parcela) & 866,75 & 872,48 & 871,32 & 12,41 \\
Massa seca de colmos (g/parcela) & $582,31 \mathrm{~b}$ & $702,69 \mathrm{a}$ & $557,50 \mathrm{~b}$ & 15,07 \\
Massa seca de material morto (g/parcela) & $220,84 \mathrm{a}$ & $138,66 \mathrm{~b}$ & $258,87 \mathrm{a}$ & 47,79 \\
Épocas das secas & $63,57 \mathrm{a}$ & $31,07 \mathrm{~b}$ & $55,07 \mathrm{a}$ & 8,02 \\
Massa seca total (g/parcela) & & & 1322,84 \\
Massa seca de lâminas (g/parcela) & 1289,44 & 1500,77 & 7,83 \\
Massa seca de colmos (g/parcela) & 691,13 & 797,65 & 794,21 & 11,21 \\
Massa seca de material morto (g/parcela) & $411,79 \mathrm{a}$ & $336,62 \mathrm{~b}$ & $488,32 \mathrm{a}$ & 25,56 \\
\hline Médias seguis
\end{tabular}

Médias seguidas de letra igual na linha não diferem entre si pelo teste Tukey a 5\% de probabilidade para o erro tipo I.

$\mathrm{Na}$ tabela 5 observam-se composições bromatológicas na época das secas das cultivares Marandu, Xaraés e Piatã que não diferiram entre si $(\mathrm{P}>0,05)$ quando analisadas as composições de qualidade para proteína bruta do colmo, FDN do colmo, FDA do colmo, DIVMO do colmo e lignina das folhas e do colmo. As cultivares Marandu e Piatã não diferiram entre si $(\mathrm{P}>0,05)$ quanto às características de $\mathrm{PB}$ das folhas, observando-se maiores valores dessas (16,5 e
$16,8 \%$, respectivamente), quando comparadas com a cultivar Xaraés $(15,1 \%)$.

Também para FDN e FDA das folhas e DIVMO das folhas observou-se semelhança (P > $0,05)$ entre as cultivares Marandu e Piatã, com maiores valores de FDN e menores valores de FDA e DIVMO observados para a cultivar Xaraés (Tabela 5). Em relação ao teor de FDN, o capimmarandu apresentou $70,2 \%$ de FDN e $34,7 \%$ de FDA na época das secas.

Tabela 5. Médias de características de qualidade de cultivares da espécie Urochloa brizantha na Época das secas.

\begin{tabular}{lccrr}
\hline \multirow{2}{*}{ Característica } & \multicolumn{3}{c}{ Cultivar } & C.V.(\%) \\
\cline { 2 - 4 } Proteína Bruta Folhas & Marandu & Xaraés & \multicolumn{1}{c}{ Piatã } & 2,91 \\
Proteína Bruta colmo & $16,53^{\mathrm{a}}$ & $15,10^{\mathrm{b}}$ & $16,80^{\mathrm{a}}$ & 10,91 \\
FDN $^{1}$ Folhas & 8,46 & 8,03 & 9,43 & 1,48 \\
FDN $^{1}$ colmo & $70,23^{\mathrm{b}}$ & $74,16^{\mathrm{a}}$ & $70,90^{\mathrm{b}}$ & 1,79 \\
FDA $^{2}$ folhas & 82,16 & 81,93 & 81,20 & 1,97 \\
FDA $^{2}$ colmo & $34,71^{\mathrm{b}}$ & $37,35^{\mathrm{a}}$ & $34,60^{\mathrm{b}}$ & 4,35 \\
DIVMO $^{3}$ folhas & 46,36 & 48,06 & 44,26 & 4,14 \\
DIVMO $^{3}$ colmos & $69,27^{\mathrm{a}}$ & $59,50^{\mathrm{b}}$ & $69,40^{\mathrm{a}}$ & 4,23 \\
Lignina folha & 55,60 & 53,00 & 58,36 & 3,77 \\
Lignina colmo & 5,20 & 3,20 & 3,16 & 6,69 \\
\hline
\end{tabular}

Médias seguidas da mesma letra na linha não diferem entre si pelo teste Tukey a 5\% de probabilidade para o erro tipo I. ${ }^{1}$ Fibra em detergente neutro. ${ }^{2}$ Fibra em detergente ácido. ${ }^{3}$ Digestibilidade in vitro da matéria orgânica

$\mathrm{Na}$ tabela 6 observam-se as médias de características de qualidade de cultivares da espécie Urochloa brizantha na época seca do ano. Não houve diferença $(P>0,05)$ entre as cultivares avaliadas para os valores de (PB) nas folhas e no colmo.

Não foi observado diferença $(\mathrm{P}>0,05)$ entre as cultivares avaliadas para as características de FDN do colmo, FDA das folhas e de colmo, e lignina na folha e no colmo. Analisando os dados de FDN folhas observa-se que a cultivar Xaraés apresentou maior proporção de FDN folhas quando comparada às demais cultivares $(72,2 \%)$. Além disso, a cultivar Xaraés diferiu significativamente $(\mathrm{P} \leq 0,05)$ das cultivares Piatã e Marandu para característica de DIVMO de folhas e colmo, se apresentando com baixos valores de digestibilidade quando comparada às demais. 
Tabela 6. Médias em percentagem de características de qualidade de cultivares da espécie Urochloa brizantha na época seca.

\begin{tabular}{lcccr}
\hline \multirow{2}{*}{ Características } & \multicolumn{3}{c}{ Cultivares } & CV(\%) \\
\cline { 2 - 4 } & Marandu & Xaraés & Piatã & 9,33 \\
\hline Proteína bruta folhas & 9,53 & 8,33 & 10,23 & 8,31 \\
Proteína bruta colmo & 4,56 & 4,26 & 4,83 & 1,02 \\
FDN $^{1}$ folhas & $69,96^{\mathrm{b}}$ & $72,20^{\mathrm{a}}$ & $69,73^{\mathrm{b}}$ & 1,07 \\
FDN $^{1}$ colmo & 75,66 & 74,56 & 73,23 & 4,35 \\
FDA $^{2}$ folhas & 46,36 & 48,06 & 44,26 & 2,93 \\
FDA $^{2}$ colmo & 40,93 & 41,13 & 39,16 & 3,73 \\
DIVMO $^{3}$ folhas & $65,53^{\mathrm{a}}$ & $58,60^{\mathrm{b}}$ & 3,66 \\
DIVMO & colmos & $51,90^{\mathrm{b}}$ & $57,73^{\mathrm{a}}$ & 10,86 \\
Lignina folha & $54,10^{\mathrm{a}}$ & 3,20 & 3,16 & 5,36 \\
Lignina colmo & 2,60 & 3,76 & 3,70 & \\
\hline
\end{tabular}

Médias seguidas da mesma letra na linha não diferem entre si pelo teste Tukey a 5\% de probabilidade para o erro tipo I. ${ }^{1}$ Fibra em detergente neutro. 2Fibra em detergente ácido. ${ }^{3}$ Digestibilidade in vitro da matéria orgânica

\section{Discussão}

Em relação a produtividade, o capim-massai torna-se mais nutritivo e mais adaptado à região pelo maior índice de produção de folhas em relação ao colmo e por se apresentar de menor porte em relação às demais cultivares avaliadas (Lopes et al., 2013).

Já, a alta produtividade de material morto do capim-massai pode ser explicada pelo fato de que essa cultivar apresenta maior números de perfilhos em relação às demais, o que contribui para o aparecimento de novas folhas induzindo a senescência de folhas velhas no período das águas. Enquanto que, a baixa produção e MM para a cultivar Milênio pode ser explicada devido a sua menor quantidade de MST em relação às demais.

Pode-se destacar no período seco, que a característica de MST apresentou valores superiores para todas as cultivares avaliadas em detrimento ao período das águas, o que pode ser explicado pela incidência de chuvas no mês de janeiro (não muito comum na região Agreste) que é considerado período das secas. O capim Massai apresentou-se com maior vigor e capacidade de sobrevivência nas condições do verão do Agreste alagoano, uma vez que na época crítica do ano apresentou menor produção de material morto quando comparado às outras cultivares da mesma espécie.

Os valores médios para proteína bruta de folhas foram sempre superiores aos da proteína bruta de colmo, corroborando os resultados reportados por Gerdes et al. (2000) e Cano et al. (2004), ao trabalharem com o mesmo cultivar.

Em relação ao valor qualitativo, a cultivar Massai apresentou menor valor para proteína de colmo, o que era esperado, uma vez que este capim possui menor proporção de colmo por se apresentar como a cultivar de menor porte em relação às demais. Além disso, o capim Massai apresenta menor proporção de MS em relação às demais devido ao seu menor porte, o que pode ter contribuído para um baixo FDN das folhas.

Em geral, os dados de FDN e FDA das folhas foram menores em detrimento do FDN e FDA do colmo para todas as cultivares avaliadas, o que pode ser explicado pelo maior teor de lignificação da parede celular no colmo em relação às folhas.

Para características de digestibilidade, os dados demonstram que, para período de avaliação, os resultados da variável DIVMO das folhas foi sempre superior à DIVMO do colmo, o que corrobora com os dados de Cano et al. (2004). Esse fato pode ser explicado pela alta lignificação da parede celular contida no colmo por ser o órgão responsável pela sustentação da planta.

Além disso, a matéria seca do colmo elevada em todas as cultivares avaliadas, pode ser explicada pelo aumento da produtividade (matéria seca total) no período crítico do ano. É desejável que a fração da matéria seca da lâmina apresentese maior, uma vez que esta é a porção de maior valor nutricional e preferencialmente selecionada pelos animais (Santini et al., 2015) e quanto menor for a produção de material morto da cultivar maior será o indicativo de produção de lâmina foliar. Assim, pode-se afirmar que na época das secas a cultivar Xaraés apresentou-se com maior valor de biomassa laminar.

Segundo NRC (2000), o valor limitante de PB para a produção animal é de $7 \%$ com base na matéria seca. Valor abaixo deste como observado 
para as gramíneas avaliadas nesse experimento pode ser justificada pela alta incidência de precipitação pluviométrica na época das chuvas que juntamente com a alta intensidade luminosa aumenta o teor fotossintético e promove maior assimilação de nutrientes às plantas. Ademais as adubações potássica e nitrogenada foram realizadas nessa mesma época, o que também pode ter colaborado para o aumento nos teores de PB nas cultivares Marandu e Piatã, apesar da não significância observada.

O teor de FDN é um importante parâmetro que define a qualidade da forragem, sendo que valores acima de 55 a $60 \%$ correlacionam-se negativamente com o consumo voluntário dos animais (Van Soest, 1994). De acordo com os resultados, pode-se inferir que a cultivar Xaraés é a de menor valor nutritivo em proporções de FDN e DIVMO enquanto que a cultivar Marandu se apresentou com melhor valor nutritivo. Santos et al. (2008) estudando a composição química da Urochloa brizantha (capim Marandu) e Urochloa decumbens (capim Basilisk) submetidas a diferentes níveis de adubação nitrogenada não observaram nenhuma diferença de FDN e FDA na composição bromatológica das forrageiras, sendo os valores iguais a 65,4 e $39,3 \%$, respectivamente, valores próximos aos obtidos neste estudo com o capim Marandu.

Ainda, observa-se de forma geral que os valores nutritivos das gramíneas tropicais durante o período de seca apresentaram-se baixos. O nitrogênio é um dos principais constituintes da proteína que participa ativamente na síntese de compostos orgânicos necessários ao metabolismo vegetal (Taiz \& Zeiger, 2009). Em estudo com doses de nitrogênio e fósforo no capim-braquiária, Costa et al. (2007) e Magalhães et al. (2007) verificaram que apenas o $\mathrm{N}$ influenciou nos teores de PB. Assim, a ausência da adubação neste estudo, juntamente com a baixa precipitação pluviométrica no período seco do ano pode ter ocasionado a diminuição nos valores de PB.

\section{Conclusões}

Foi possível concluir com este trabalho que a cultivar Tanzânia da espécie $P$. maximum apresentou-se qualitativamente superior as demais com maior digestibilidade e maior conteúdo proteico. Porém, a cultivar Massai apresentou-se mais produtiva em relação às demais.

As cultivares de $P$. maximum apresentaram padrões de desenvolvimento semelhantes e compatíveis com outras regiões. Entretanto, estudos de repetibilidade e avaliação sob pastejo devem ser conduzidos, uma vez que esse estudo é pioneiro na avaliação e seleção de cultivares de Panicum para o Agreste alagoano, região carente de tecnologias e opções de forrageiras para estabelecimento de uma pecuária competitiva exigida no mercado atual.

Dentre as cultivares de $U$. brizantha, é possível afirmar que o capim-xaraés e o capim-marandu apresentaram-se mais adaptados à região do Agreste Alagoano por terem contemplado maior produtividade e melhor qualidade. No entanto, outros estudos precisam ser elaborados para conclusões mais precisas acerca dessa afirmativa.

\section{Referências bibliográficas}

ANUALPEC. 2017. Anuário da Pecuária Brasileira, 20th edn. Instituto FNP, São Paulo, SP, Brasil.

Argenta, F. M., Brondani, I. L., Alves Filho, D. C., Nornberg, J. L., Segabinazi, L. R., Restle, J., Weise, M. S., Borchate, D., da Silva Rodrigues, L. \& de Moura, A. F. 2017. Comportamento ingestivo de novilhos alimentados com silagem de capim papuã (Urochloaplan taginea) x silagem de sorgo (Sorghum bicolor (L.) Moench). Revista Acadêmica: Ciência Animal, 11, 243-253.

Cano, C. C. P., Cecato, U., Canto, M. W., Santos, G. T., Galbeiro, S., Martins, E. N. \& Mira, R. T. 2004. Nutritive value of Tanzania grass (Panicum maximum Jacq.cv. Tanzânia-1) grazed at different heights. Revista Brasileira de Zootecnia, 33, 1959-1968.

Costa, K. A. P., Oliveira, I. P., Faquin, V., Neves, B. P., Rodrigues, C. \& Sampaio, F. d. M. T. 2007. Intervalo de corte na produção de massa seca e composição químico-bromatológica da Brachiaria brizantha cv. MG-5. Ciência Agrotecnologia, 31, 1197-1202.

EMBRAPA. 2006. Sistema brasileiro de classificação de solos.

FAO. 2015. Statistical Yearbook. Food and Agriculture Organization of the United Nations, Rome, Italy.

Ferraz, J. B. S. \& Felício, P. E. 2010. Production systems - An example from Brazil. Meat Science, 84, 238-243.

Ferrazza, R. A., Lopes, M. A., de Moraes, F. \& Pascoti Bruhn, F. R. 2015. Índices de desempenho zootécnico e econômico de 
sistemas de produção de leite com diferentes níveis tecnológicos. Semina: Ciências Agrárias, 36, 485-496.

Freitas, F. P., Fonseca, D. M., Santos Braz, T. G., Martuscello, J. A. \& Santos, M. E. R. 2012. Forage yield and nutritive value of Tanzania grass under nitrogen supplies and plant densities. Revista Brasileira de Zootecnia, 41, 864-872.

Gerdes, L., Werner, J. C., Colozza, M. T., Possenti, R. A. \& Schammass, E. A. 2000. Avaliação de características de valor nutritivo das gramíneas forrageiras Marandu, Setária e Tanzânia nas estações do ano. Revista Brasileira de Zootecnia, 29, 955-963.

Köppen, W. \& Geiger, R. 1928. Klimate der Erde. Gotha: Verlag Justus Perthes. Wall-map $150 \mathrm{~cm} \times 200 \mathrm{~cm}$.

Lopes, M. N., Cândido, M. J. D., Pompeu, R. C. F. F., Silva, R. G., Lopes, J. W. B., Fernandes, F. R. B., Lacerda, C. F. \& Bezerra, F. M. L. 2013. Fluxo de biomassa em capim-massai durante o estabelecimento e rebrotação com e sem adubação nitrogenada1. Revista Ceres, 60 , 363-371.

Magalhães, A. F., Pires, A. J. V., Carvalho, G. G. P., Silva, F. F., Sousa, R. S. \& Veloso, C. M. 2007. Influência do nitrogênio e do fósforo na produção do capim-braquiária Influence of nitrogen and phosphorus on Brachiaria decumbens stapf. production. Revista Brasileira de Zootecnia, 36, 1240-1246.

Martuscello, J. A., Braz, T. G. S., Jank, L., Cunha, D. N. F. V., Lima, B. P. S. \& Oliveira, L. P. 2015. Repeatability and phenotypic stabilization of Panicum maximum accessions. Acta Scientiarum. Animal Sciences, 37, 15-21.
Martuscello, J. A., Jank, L., Fonseca, D. M. d., Cruz, C. D. \& Cunha, D. d. N. F. V. 2007. Agronomic characters repeatability in Panicum maximum Jacq. Revista Brasileira de Zootecnia, 36, 1975-1981.

NRC. 2000. Nutrient Requirements of Beef Cattle, 7th rev. edn. Natl. Acad. Press, Washington, DC, USA.

Santini, J. M. K., Buzetti, S., Galino, F. S., Dupas, E. \& Coaguila, D. N. 2015. Técnicas de manejo para recuperação de pastagens degradadas de capim-braquiária (Brachiaria decumbens Stapf cv. Basilisk). Boletim de Indústria Animal, 72, 331-340.

Santos, L. C., Bonomo, P., Silva, C. C. F., Pires, A. J. V., Veloso, C. M. \& Silva Patês, N. M. 2008. Produção e composição química da Brachiaria brizantha e Brachiaria decumbens submetidas a diferentes adubações. Ciência Animal Brasileira, 9, 856-866.

Silva, S. C. \& Nascimento Júnior, D. 2007. Avanços na pesquisa com plantas forrageiras tropicais em pastagens: características morfofisiológicas e manejo do pastejo. Revista Brasileira de Zootecnia, 36, 122-138.

Taiz, L. \& Zeiger, E. 2009. Fisiologia vegetal. Artmed, Porto Alegre, Brasil.

Van Soest, P. J. 1994. Nutritional ecology of the ruminant. Cornell University Press, Ithaca, NY, USA.

\section{Article History:}

Received 19 December 2017

Accepted 30 January 2018

Available online 29 March 2018

License information: This is an open-access article distributed under the terms of the Creative Commons Attribution License 4.0, which permits unrestricted use, distribution, and reproduction in any medium, provided the original work is properly cited. 